\title{
Disaggregated consumer prices and oil price pass-through: evidence from Malaysia
}

\begin{abstract}
Purpose: The purpose of this paper is to analyze the oil price pass-through into consumer price inflation for a developing country: Malaysia. The focus is on whether aggregate consumer prices and different consumer price components or sub-price indexes are related in different ways to oil price in the long run and in the short run.

Design/methodology/approach: The analysis adopts the Phillips curve framework augmented to include the oil price. In modeling, a proper consideration is given to the integration and cointegration properties of the variables under consideration. Moreover, the asymmetric effects of oil price changes are also examined.

Findings: The paper finds evidence for a long run relation or cointegration of the oil price with only the aggregate consumer price and food price indexes. Moreover, in the short run, the oil price changes have significant bearings on the consumer price inflation, the food price inflation, the rent, fuel and power price inflation and the transportation and communication price inflation. In addition, the short-run asymmetry in the oil price $\ddot{i}$ food price inflation is also evident. Finally, the authors observe the neutrality of the medical care and health price index to the oil price changes.

Practical implications: The result that the inflationary consequence of oil price hikes is likely to work mainly through the food prices has important implications on the effects of oil price changes on the poor and policy directions to contain inflation.

Originality/value: The paper contributes to existing literature that has a predominant focus on the inflationary effect of oil prices at the aggregate level by looking at the relations between oil price and disaggregated good prices in the long run, short run, or both.
\end{abstract}

Keyword: Oil price pass-though; Disaggregated consumer prices; Augmented Phillips curve; Prices; Oil industry; Malaysia 